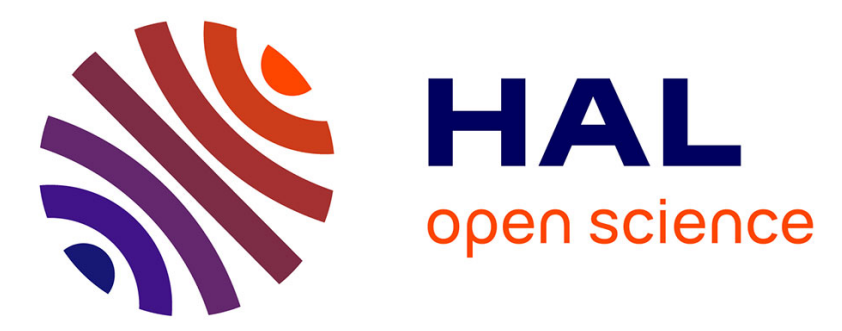

\title{
Application of the Valence Bond Mixing Configuration Diagrams to Hypervalency in Trihalide Anions: A Challenge to the Rundle-Pimentel Model
}

\author{
Benoît Braïda, Philippe C. Hiberty
}

\section{- To cite this version:}

Benoît Braïda, Philippe C. Hiberty. Application of the Valence Bond Mixing Configuration Diagrams to Hypervalency in Trihalide Anions: A Challenge to the Rundle-Pimentel Model. Journal of Physical Chemistry A, 2008, 112 (50), pp.13045-13052. 10.1021/jp803808e . hal-01627705

\section{HAL Id: hal-01627705 https://hal.science/hal-01627705}

Submitted on 21 Nov 2017

HAL is a multi-disciplinary open access archive for the deposit and dissemination of scientific research documents, whether they are published or not. The documents may come from teaching and research institutions in France or abroad, or from public or private research centers.
L'archive ouverte pluridisciplinaire HAL, est destinée au dépôt et à la diffusion de documents scientifiques de niveau recherche, publiés ou non, émanant des établissements d'enseignement et de recherche français ou étrangers, des laboratoires publics ou privés. 


\title{
Application of the Valence Bond Mixing Configuration Diagrams to Hypervalency in Trihalide Anions: A Challenge to the Rundle-Pimentel Model ${ }^{\dagger}$
}

\author{
Benoît Braïda and Philippe C. Hiberty*,\$ \\ Laboratoire de Chimie Théorique, 4 place Jussieu, Case courrier 137, UPMC Université Paris 06, CNRS UMR \\ 7616, 75252 Paris, France, and Laboratoire de Chimie Physique, Bât 490, Université de Paris-Sud, CNRS \\ UMR 8000, 91405 Orsay, France
}

\begin{abstract}
The $\mathrm{X}_{3}{ }^{-}$hypercoordinated anions $(\mathrm{H}, \mathrm{F}, \mathrm{Cl}, \mathrm{Br}, \mathrm{I})$ are studied by means of the breathing-orbital valence bond $\mathrm{ab}$ initio method. The valence bond wave functions describe the different $\mathrm{X}_{3}{ }^{-}$complexes in terms of only six valence bond structures and yield energies relative to the two exit channels, $\mathrm{X}_{2}+\mathrm{X}^{-}$and $\mathrm{X}_{2}{ }^{-}+\mathrm{X}^{\cdot}$, in very good agreement with reference $\operatorname{CCSD}(\mathrm{T})$ calculations. Although $\mathrm{H}_{3}{ }^{-}$is unstable and dissociates to $\mathrm{H}_{2}+\mathrm{H}^{-}$, all the trihalogen anions are stable intermediates, $\mathrm{Br}_{3}{ }^{-}$and $\mathrm{I}_{3}{ }^{-}$being more stable than $\mathrm{F}_{3}{ }^{-}$and $\mathrm{Cl}_{3}{ }^{-}$. As a challenge to the traditional Rundle-Pimentel model, the different energies of the hypercoordinated species relative to the normal-valent dissociation products $\mathrm{X}_{2}+\mathrm{X}^{-}$are interpreted in terms of valence bond configuration mixing diagrams and found to correlate with a single parameter of the $\mathrm{X}_{2}$ molecule, its singlet-triplet energy gap. Examination of the six-structure wave functions show that $\mathrm{H}_{3}{ }^{-}, \mathrm{Cl}_{3}{ }^{-}, \mathrm{Br}_{3}{ }^{-}$, and $\mathrm{I}_{3}{ }^{-}$share the same bonding picture and can be mainly described in terms of the interplay of two Lewis structures. On the other hand, $\mathrm{F}_{3}{ }^{-}$is bonded in a different way and possesses a significant three-electron bonding character that is responsible for the dissociation of this complex to $\mathrm{F}_{2}{ }^{-}+\mathrm{F}^{*}$, instead of the more stable products $\mathrm{F}_{2}+\mathrm{F}^{-}$. This counterintuitive preference for the thermodynamically disfavored exit channel is found to be an experimental manifestation of the large charge-shift resonance energy that generally characterizes fluorine-containing bonds.
\end{abstract}

\section{Introduction}

One of the greatest achievements of Sason Shaik was the elaboration of the valence bond state correlation diagrams, that started with a landmark 1981 paper entitled "What Happens to Molecules as They React". ${ }^{1}$ By tracing the energies of the VB configurations along the reaction coordinates, such diagrams bring some unique insight on the reaction mechanisms, reveal the cause of the barrier, the nature of the transition state, and the reason for occurrence of intermediates. ${ }^{2-6}$ Moreover, they allow predictions to be made on the trends of activation energies in series of reactions, from the sole knowledge of the properties of reactants and/or products. The valence bond state correlation diagrams (VBSCD) model applies to the general category of reactions that can be described as an interplay of two major VB structures, that of the reactants and that of the products. An extension of the model, called valence bond configuration mixing diagrams (VBCMD), was later devised for systems that are best described as the interaction of three VB structures or more. ${ }^{2-6}$ Thus, the general model applies to a wide category of reactions, but also to hypervalent compounds, since the latter can always be viewed as transition states or intermediates in exchange reactions involving normal-valent compounds. As examples among others, the stability of $\mathrm{Li}_{3}{ }^{\cdot}$ and $\mathrm{Na}_{3}{ }^{\bullet}$ radicals versus unstability of $\mathrm{H}_{3}{ }^{\bullet}$ is easily rationalized, ${ }^{7}$ and VBCMDs elegantly explain why $\mathrm{SiH}_{5}{ }^{-}$is a stable hypervalent anion, whereas isoelectronic $\mathrm{CH}_{5}{ }^{-}$is a high-lying transition state, ${ }^{8,9}$

\footnotetext{
† Part of the "Sason S. Shaik Festschrift".

* Corresponding author. E-mail: philippe.hiberty@u-psud.fr. Fax: +(33)1-69156188. Tel.: +(33)-1-69156175.

¥ UPMC Université Paris 06.

$\S$ Université de Paris-Sud.
}

and why removal of just one electron makes both $\mathrm{SiH}_{5}{ }^{\circ}$ and $\mathrm{CH}_{5}{ }^{\bullet}$ unstable. ${ }^{10}$

Among hypervalent compounds, polyhalide anions $\mathrm{X}_{3}{ }^{-}(\mathrm{X}$ $=\mathrm{F}, \mathrm{Cl}, \mathrm{Br}, \mathrm{I}$ ) are prototypical examples of clusters that violate the octet rule and are held together by four-electron-three-center $(4 \mathrm{e}, 3 \mathrm{c})$ bonding. The experimental structures of these anions have been determined by spectroscopic methods. ${ }^{1-15}$ They are linear and symmetric in the gas phase and in solution, whereas in the solid state both symmetric and asymmetric structures are found, ${ }^{16,17}$ owing to crystal packing forces. The first trihalide anion to be detected in the gas phase was $\mathrm{I}_{3}{ }^{-}$in $1928,{ }^{18}$ followed by $\mathrm{Cl}_{3}{ }^{-}$in $1958,{ }^{19}$ while the gas-phase detection of $\mathrm{Br}_{3}{ }^{-}$and $\mathrm{F}_{3}{ }^{-}$was realized only one decade ago. ${ }^{20,21}$ These species are all stable against dissociation by either exit channels, eqs 1 and 2 , with channel 1 being in all cases the thermodynamically favored one. ${ }^{22-24}$

$$
\begin{aligned}
& \mathrm{X}_{3}^{-} \rightarrow \mathrm{X}_{2}+\mathrm{X}^{-} \\
& \mathrm{X}_{3}^{-} \rightarrow \mathrm{X}_{2}^{-}+\mathrm{X}^{\bullet}
\end{aligned}
$$

The trihalide dissociation energies in the gas phase were experimentally measured by Sunderlin and co-workers, using energy-resolved collision-induced dissociation (CID) in a flowing-afterglow mass spectrometer. ${ }^{22-24}$ Remarkably, the bond strengths of these hypervalent compounds, defined as the dissociation energies relative to the exit channel 1 , are quite significant and amount to $29-32 \mathrm{kcal} / \mathrm{mol}$ for $\mathrm{I}_{3}{ }^{-22}, 29-32 \mathrm{kcal} /$ mol and 22-25 kcal/mol, respectively, for $\mathrm{Br}_{3}{ }^{-}$and $\mathrm{Cl}_{3}{ }^{-},{ }^{23}$ and $21-26 \mathrm{kcal} / \mathrm{mol}$ for $\mathrm{F}_{3}{ }^{-}{ }^{24}$ These rather large values, which point to a remarkable stability of the trihalide anions, are to be contrasted with the unstability of the $\mathrm{H}_{3}{ }^{-}$cluster, which is a transition state lying some $11 \mathrm{kcal} / \mathrm{mol}$ above $\mathrm{H}_{2}+\mathrm{H}^{-} .25$ This 
difference between isoelectronic systems, that are all of the fourelectron-three-center type, requires explanation.

Historically, the first model that has been used to explain hypervalent bonding was that of the octet expansion through the use of $\mathrm{d}$ orbitals. ${ }^{26}$ In this model, a postulated $\mathrm{sp}^{3} \mathrm{~d}$ hybridization of the central atom would allow the latter to be formally surrounded by five bonds or lone pairs, as is the case for trihalide anions. However, this model has been ruled out by Reed and Schleyer, ${ }^{27}$ who showed by theoretical calculations that hypervalency would persist without the help of $d$ orbitals. A more popular model is that of Pimentel and Rundle, ${ }^{28}$ based on molecular orbital (MO) theory. Restricting the reasoning in the trihalide anions to the three axial p orbitals that are involved in the $\sigma$ bonds, one forms three MOs, one bonding, one nonbonding, and one antibonding combinations. In the $(4 \mathrm{e}, 3 \mathrm{c})$ case, filling the two lowest-lying MOs leads to a bonding picture involving two bonding electrons and two nonbonding ones, and no antibonding occupied MO, hence the stability of the cluster. This is of course a rough picture, which neglects many factors among which hybridization of the atomic orbitals of the highest occupied MOs, which adds some antibonding character to the allegedly nonbonding MO. ${ }^{29}$ The amount of hybridization, as well as the repulsive interactions arising from the lower MOs and their consequence on the stability of $\mathrm{X}_{3}{ }^{-}$and isoelectronic clusters, have been studied in details by Munzarova and Hoffmann. ${ }^{29}$ Now, however attracting as it may look, the logic of the Rundle-Pimentel model fails in the case of $\mathrm{H}_{3}{ }^{-}$, which is unstable despite the fact that the two occupied MOs of this anionic cluster are, respectively, bonding and nonbonding, in close analogy with the stable trihalide anions.

Another puzzling feature of trihalide anions is some kind of "fluorine exception", by which the trifluoride anion dissociates primarily via exit channel 2 , at high collision energy with argon $(25 \mathrm{eV}),{ }^{21}$ although this reaction is thermodynamically less favorable than channel 1 . Thus, the three-electron-bonded $\mathrm{F}_{2}{ }^{-}$ radical is 3 times more abundant than $\mathrm{F}^{*}$ in the dissociation products. This unexpected branching ratio was explained in a previous work, ${ }^{30}$ as due to a slightly dominant three-electron bonding character in the $\mathrm{F}_{3}{ }^{-}$cluster. By contrast, CID of $\mathrm{X}_{3}{ }^{-}$ leads to an $\mathrm{X}_{2}{ }^{-} / \mathrm{X}^{*}$ cross section of 50 for $\mathrm{X}=\mathrm{Cl}, 20$ for $\mathrm{X}=$ $\mathrm{Br}$, and 10 for $\mathrm{X}=\mathrm{I}$, in accord with the decreasing energy gap between the two channels and in qualitative agreement with thermodynamical control. ${ }^{23}$ Even if the collisions energies are different, $25 \mathrm{eV}$ for $\mathrm{F}_{3}{ }^{-}$versus $4 \mathrm{eV}$ for $\mathrm{Cl}_{3}{ }^{-}, \mathrm{Br}_{3}{ }^{-}$, and $\mathrm{I}_{3}{ }^{-}$, this difference is intriguing and might reflect some fundamental difference of bonding nature between $\mathrm{F}_{3}{ }^{-}$and the other trihalide anions.

It is clear that the Rundle-Pimentel model of $(4 \mathrm{e}, 3 \mathrm{c})$ hypervalency leaves open a number of questions: (i) Why is $\mathrm{H}_{3}{ }^{-}$unstable, whereas trihalide anions are quite stable hypervalent compounds? (ii) What is the nature of $\mathrm{X}_{3}{ }^{-}$bonding for $\mathrm{X}=\mathrm{Cl}, \mathrm{Br}$, I and is it different from the trifluoride case? (iii) Why do not $\mathrm{Cl}_{3}{ }^{-}, \mathrm{Br}_{3}{ }^{-}$, and $\mathrm{I}_{3}{ }^{-}$primarily dissociate by the exit channel 2 like $\mathrm{F}_{3}{ }^{-}$? And finally, (iv) can the dissociation energies of all $\mathrm{X}_{3}{ }^{-}$species be related to properties of normal-valent compounds, $\mathrm{X}_{2}$ ?

The answer to the above specific questions about trihalide anions require a qualitative understanding of their electronic structure, and this can be achieved only with the help of a compact wave function which, despite its compactness, incorporates the essential ingredients that are required for a realistic description of the ground state and, in particular, electron correlation. Such requirements are fulfilled by the "breathingorbital valence bond" method (BOVB), ${ }^{31}$ a modern ab initio
SCHEME 1

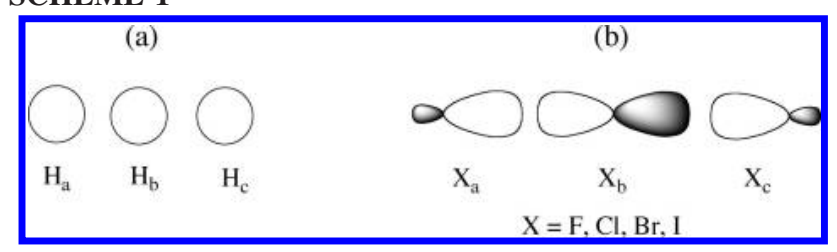

VB method that has been devised to combine the simplicity and interpretability of the classical VB description (only six VB structures here) with reasonable accuracy. As has been successfully done in the past for other hypervalent compounds, ${ }^{7,8}$ the bonding energies of the trihalide anions as well as the instability of the $\mathrm{H}_{3}{ }^{-}$transition state will be interpreted in terms of the VBCMD model, supported by the ab initio calculations.

\section{Theory and Methodology}

Breathing-Orbital Valence Bond Method. The BOVB method is an ab initio computational method of valence bond type that has been devised to combine the properties of interpretability and extreme compactness of the wave function, with reasonable accuracy of the calculated energies. ${ }^{31}$ The wave function $\Psi$ is composed of a set of VB structures $\Phi_{K}$ that forms a complete and minimal set (also called Rumer basis ${ }^{6,32}$ ) for the description of a given electronic state (eq 3 ).

$$
\Psi=\sum_{K} C_{K} \Phi_{K}
$$

Among the electrons and orbitals, one distinguishes an active space, made of the orbitals and the electrons that are directly involved in the bond breaking/forming, from an inactive space, where the orbitals keep the same occupancy throughout the dissociation coordinate. In the $\mathrm{X}_{3}{ }^{-}$trimer $(\mathrm{X}=\mathrm{F}, \mathrm{Cl}, \mathrm{Br}, \mathrm{I})$, the inactive space is composed of the nine lone pairs, whereas the active space involves four electrons and three orbitals: a pure atomic $\mathrm{p}$ orbital on the central atom, and one sp hybrid orbital on each of the remaining atoms. $\mathrm{In}_{3}{ }^{-}$, all the electrons and orbitals belong to the active space (see Scheme 1).

The active space is treated at the VB level, and its electrons are explicitly correlated, whereas the inactive part of the molecule is described as a set of doubly occupied orbitals so that the correlation of inactive electrons and the active-inactive correlation are not explicitly taken into account. An important feature of our VB calculations is that all the active orbitals are strictly localized on a single fragment $\mathrm{X}$, like in the classical VB method, so as to ensure a clear correspondence between the mathematical expressions of the VB structures and their physical meaning, ionic or covalent. The coefficients and orbitals of the VB structures are optimized simultaneously, so as to minimize the total energy of the multistructure wave function. During the optimization process, each VB structure is allowed to possess its specific set of orbitals, different from one VB structure to the other. In this manner, the orbitals can fluctuate in size and shape so as to fit the instantaneous charges of the atoms on which these orbitals are located. This specificity of the BOVB method ensures its accuracy by bringing some dynamic correlation to the wave function, without increasing the number of VB configurations. It may be noted that a calculation of nearly equivalent accuracy, in the MO framework, would consist of performing a complete active space multiconfiguration self-consistent field calculation (CASSCF) followed by a configuration interaction involving all single excitations generated from the CAS determinants. Indeed, although the CASSCF calculation brings the nondynamical correlation 


\begin{tabular}{ccc}
\hline$X^{-} X_{\bullet-\bullet X}$ & $X^{-} X^{-} X^{+}$ & $X^{-} X^{+} X^{-}$ \\
1 & 2 & 3 \\
$X^{+} X^{-} X^{-}$ & $X \bullet-X X^{-}$ & $X^{-} X^{-} X \cdot$ \\
4 & 5 & 6 \\
\hline
\end{tabular}

energy, the further single excitations have an effect equivalent to an optimization of the orbitals independently for each determinant, similar in spirit to the "different-orbital-fordifferent-configurations" principle of the BOVB method.

The BOVB method has a few levels which differ in hierarchy of sophistication. Here we use the most sophisticated level, referred to as SD-BOVB. This level is characterized by two improvements relative to the basic level: (i) the active doubly occupied orbitals of an ionic structure are split into two singletcoupled singly occupied orbitals, so as to bring some radial correlation to the active electrons; (ii) the lone pairs are allowed to be delocalized on the three fragments. This does not change the physical meaning of the VB structures but allows some flexibility in the interactions between lone pairs. Last, in the $\mathrm{H}_{3}{ }^{-}$case, further VB structures displaying $\mathrm{p}$ occupied orbitals for $\mathrm{H}^{-}$or $\mathrm{H}_{2}$ are added to bring some angular correlation. Previous experience has shown us that such VB structures are not entirely negligible in diatomic molecules with unsaturated shells such as $\mathrm{H}_{2}, \mathrm{Li}_{2}$, etc. Such structures have small coefficients and will not be considered in the analysis of the wave functions but are important for improving the accuracy of the calculated energies. Note that analogous structures do not exist in trihalide anions, since the $\mathrm{p}$ orbital system of these species are saturated.

The Set of Valence Bond Structures. In the general case, a complete and linearly independent set of VB structures for a given electronic system is entirely determined by the graphical method of Rumer. 6,32 In the four-electron-three-orbital system at hand, Rumer's method is particularly simple and consists of generating all the possible arrangements of four electrons into three orbitals that can form a singlet state. This leads to the six VB structures displayed in Scheme 2.

These structures can be interpreted according to their relevance to eq 4

$$
\mathrm{X}^{-}+\mathrm{X}_{2} \rightarrow[\mathrm{X} \cdot \mathrm{X} \cdot \mathrm{X}]^{-} \rightarrow \mathrm{X}_{2}+\mathrm{X}^{-}
$$

in which the hypervalent species $\mathrm{X}_{3}{ }^{-}$is considered as a transition state or intermediate in a formal exchange reaction between normal-valent species. Thus, structure $\mathbf{1}$ describes a covalent $\mathrm{X}-\mathrm{X}$ bond in the reactants, whereas $\mathbf{2}$ and $\mathbf{3}$ correspond to the ionic components of the same bond. Similarly, the ionic structures $\mathbf{3}$ and $\mathbf{4}$ and the covalent structure $\mathbf{5}$ suffice to describe the products. Note that $\mathbf{3}$ is involved in both reactants and products. The status of $\mathbf{6}$ is special. It is expected, by mere inspection, to have zero weight in the reactants' and products' geometries, but it mixes with $\mathbf{1} \mathbf{- 5}$ in the symmetrical geometry of $\mathrm{X}_{3}{ }^{-}$. As this structure is nonbonding, its weight is expected to be marginal even in $\mathrm{X}_{3}{ }^{-}$; however, it will be seen that the contribution of $\mathbf{6}$ is far from being negligible in some cases.

Valence Bond Configuration Diagrams. A general VBCMD is illustrated in Figure 1 for the formal exchange reaction 1. The reaction coordinate is the geometrical deformation of the $\mathrm{X}_{3}{ }^{-}$system from the geometry of the reactants to that of the products, via the symmetrical geometry of the $\mathrm{X}_{3}{ }^{-}$complex. The ascending dotted line features the energy of the Lewis structure of the reactants, as calculated as an optimized combination of structures $\mathbf{1 - 3}$, throughout the reaction coordinate. Similarly, the descending dotted line represents the Lewis

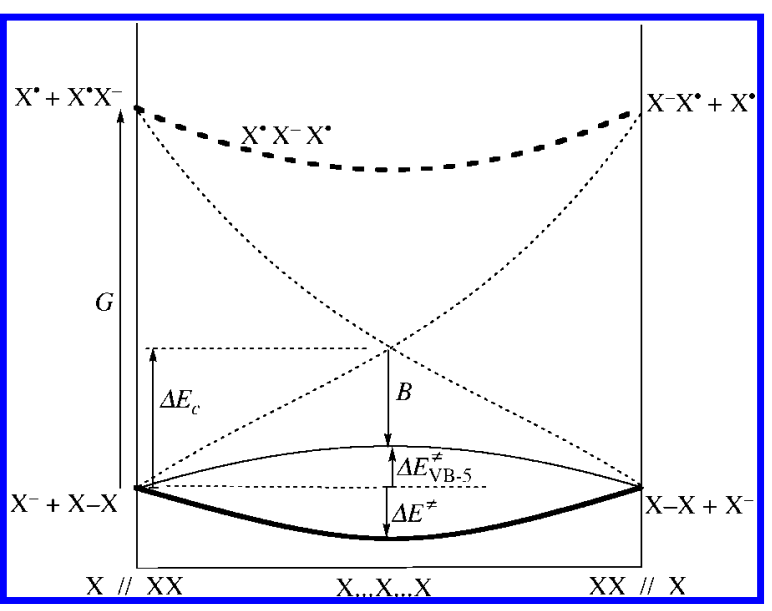

Figure 1. Typical valence bond mixing configuration diagram for the reaction $\mathrm{X}_{2}+\mathrm{X}^{-} \rightarrow\left[\mathrm{X}_{3}\right]^{-} \rightarrow \mathrm{X}^{-}+\mathrm{X}_{2}$.

structure of the products (combination of $\mathbf{3 - 5}$ ). The thin full line corresponds to the ground-state reaction profile that one would obtain by restricting the calculation to the reactants' and products' Lewis structures, i.e., restricting the set of VB structures to $\mathbf{1 - 5}$. The quantity $B$ is the resonance energy arising from the mixing of the two Lewis curves at the geometry of the avoided crossing, in the middle of the diagram. At this incomplete VB level, the calculated barrier is referred to as $\Delta E_{\mathrm{V} B}^{\neq}-5$. Finally, the bold dotted line represents the energy of the VB structure $\mathbf{6}$ alone, and the full bold line is the final ground-state profile, as obtained by including the full set of VB structures, 1-6, in the variational calculation which now yields the accurate barrier, referred to as $\Delta E^{\ddagger}$. This way of representing the VBCMD has the advantage of highlighting the stabilizing effect of structure 6, quantified as the energy difference between the thin full line and the bold full line at each point of the diagram.

Computational Details. The equilibrium distances for the $\mathrm{X}_{2}$ molecules and $\mathrm{X}_{3}{ }^{-}$clusters have been optimized at the $\operatorname{CCSD}(\mathrm{T})$ level and used in the subsequent valence bond computations. The augmented correlation-consistent triple- $\zeta$ Dunning basis set (aug-cc-pvtz) ${ }^{33}$ has been used for fluorine and chlorine compounds. For bromine and iodine compounds, the recently proposed systematically convergent triple- $\zeta$ basis sets (aug-cc-pvtz-PP) have been used together with corresponding relativistic pseudopotentials. ${ }^{34}$ Coupled cluster CCSD(T) calculations have been carried out with the Gaussian98 software, ${ }^{35}$ and the valence bond calculations with the XMVB program of the Xiamen group. ${ }^{36}$ The weights of the VB structures, displayed in Table 5, are calculated as the normalized squares of the coefficients $C_{K}$ in eq 3 .

\section{Results}

The geometries of $\mathrm{X}_{2}, \mathrm{X}_{3}{ }^{-}$, and $\mathrm{X}_{2}{ }^{-}$, as optimized at the CCSD(T) level, are displayed in Table 1 and compared with the experimental data when available, for $\mathrm{X}=\mathrm{H}, \mathrm{F}, \mathrm{Cl}, \mathrm{Br}$, and I. The geometries for $\mathrm{X}_{2}$ are in overall good agreement with the experimental values, and the errors do not increase as one goes down the periodic table, indicating a good quality of the basis set for the species that are normally the most difficult to describe, namely, $\mathrm{Br}_{2}$ and $\mathrm{I}_{2}$. As expected, the bond lengths for $\mathrm{X}_{2}{ }^{-}$are much longer than those of $\mathrm{X}_{2}$. This is because the $\mathrm{X}$ atoms in $\mathrm{X}_{2}{ }^{-}$are linked by a three-electron bond, a type of bond that is known to favor rather long interatomic distances, ${ }^{37}$ whereas $\mathrm{X}_{2}$ displays a regular two-electron single bond. For $\mathrm{X}$ 
TABLE 1: Interatomic Distances for $\mathrm{X}_{2}, \mathrm{X}_{3}{ }^{-}$, and $\mathrm{X}_{2}{ }^{-}$

\begin{tabular}{lcccc}
\hline $\mathrm{X}$ & $\mathrm{X}_{2}($ exptl $)$ & $\mathrm{X}_{2}(\mathrm{calcd})^{a}$ & $\mathrm{X}_{3}^{-}(\mathrm{calcd})^{a}$ & $\mathrm{X}_{2}^{-}(\mathrm{calcd})^{a}$ \\
\hline $\mathrm{H}$ & 0.741 & 0.743 & & \\
$\mathrm{~F}$ & 1.412 & 1.418 & 1.739 & 1.927 \\
$\mathrm{Cl}$ & 1.988 & 2.019 & 2.328 & 2.602 \\
$\mathrm{Br}$ & 2.281 & 2.296 & 2.564 & 2.820 \\
$\mathrm{I}$ & 2.665 & 2.685 & 2.945 & 3.201
\end{tabular}

${ }^{a}$ Calculated at the $\operatorname{CCSD}(\mathrm{T})$ level. All distances are in angstroms.

TABLE 2: Energy Barriers for the Reaction $\mathbf{X}_{2}+\mathbf{X}^{-} \rightarrow$ $\left[\mathbf{X}_{3}\right]^{-} \rightarrow \mathbf{X}^{-}+\mathbf{X}_{\mathbf{2}}{ }^{a}$

\begin{tabular}{lcccc}
\hline & D-BOVB & SD-BOVB & CCSD(T) & exptl \\
\hline $\mathrm{H}_{3}{ }^{-}$ & 12.9 & 12.9 & 10.6 & \\
$\mathrm{~F}_{3}{ }^{-}$ & -28.2 & -24.8 & -23.8 & $-(21$ to $\sim 26)$ \\
$\mathrm{Cl}_{3}{ }^{-}$ & -19.5 & -23.4 & -24.6 & $-(22$ to $\sim 25)$ \\
$\mathrm{Br}_{3}{ }^{-}$ & -24.4 & -28.6 & -32.2 & $-(29$ to $\sim 32)$ \\
$\mathrm{I}_{3}{ }^{-}$ & -23.0 & -28.7 & -32.8 & $-(29$ to $\sim 32)$
\end{tabular}

${ }^{a}$ This quantity refers to $\Delta E^{\ddagger}$ in Figure 1 . A positive value means an unstable transition state, and a negative value means a stable intermediate. Energies are in $\mathrm{kcal} / \mathrm{mol}$.

TABLE 3: Relative Energies of the Dissociation Products of $\mathrm{X}_{3}{ }^{-}$, in $\mathrm{kcal} / \mathrm{mol}$

\begin{tabular}{lccccc}
\hline & \multicolumn{2}{c}{ SD-BOVB } & & \multicolumn{2}{c}{$\operatorname{CCSD(T)}$} \\
\cline { 2 - 3 } \cline { 5 - 6 } $\mathrm{X}$ & $\mathrm{X}_{2}+\mathrm{X}^{-}$ & $\mathrm{X}_{2}{ }^{-}+\mathrm{X}^{\bullet}$ & & $\mathrm{X}_{2}+\mathrm{X}^{-}$ & $\mathrm{X}_{2}{ }^{-}+\mathrm{X}^{\bullet}$ \\
\hline $\mathrm{F}$ & 0 & 9.4 & & 0 & 8.6 \\
$\mathrm{Cl}$ & 0 & 23.5 & & 0 & 25.0 \\
$\mathrm{Br}$ & 0 & 16.8 & & 0 & 20.6 \\
$\mathrm{I}$ & 0 & 16.4 & & 0 & 14.5
\end{tabular}

$=\mathrm{Cl}, \mathrm{Br}$, and $\mathrm{I}$, the bond lengths for $\mathrm{X}_{3}{ }^{-}$are almost exactly halfway between those of $\mathrm{X}_{2}$ and $\mathrm{X}_{2}^{-}$. Interestingly, $\mathrm{F}_{3}{ }^{-}$is an exception, with a bond length being longer than expected and tipped toward that of $\mathrm{F}_{2}{ }^{-}$, by about $0.06 \AA$ relative to the average of $\mathrm{F}_{2}$ and $\mathrm{F}_{2}{ }^{-}$. This is a first indication that the type of bonding that dominates in $\mathrm{F}_{3}{ }^{-}$might be different from that of the other trihalogen anions.

The calculated energy barriers for reaction 4 are reported in Table 2. Besides the experimental estimations, $\operatorname{CCSD}(\mathrm{T})$ values are reported, as well as BOVB calculations at the D- and SDlevels, using the full set of VB structures 1-6 in both cases. The barrier is positive for $\mathrm{X}=\mathrm{H}$, reflecting the transition state nature of $\mathrm{H}_{3}{ }^{-}$. For $\mathrm{X}=\mathrm{F}, \mathrm{Cl}, \mathrm{Br}$, and $\mathrm{I}$, the $\mathrm{X}_{3}{ }^{-}$complex is a stable intermediate, and the negative barrier of reaction 4 measures the dissociation energy of $\mathrm{X}_{3}{ }^{-}$relative to $\mathrm{X}_{2}+\mathrm{X}^{-}$. It is seen that the trihalogen anion can be divided in two groups, $\mathrm{Br}_{3}{ }^{-}$and $\mathrm{I}_{3}{ }^{-}$being significantly more stable than $\mathrm{F}_{3}{ }^{-}$and $\mathrm{Cl}_{3}{ }^{-}$. Taking the $\operatorname{CCSD}(\mathrm{T})$ computational level as the reference, it can be seen that the accuracy of the SD-BOVB level is much better than that of the simple D-level, confirming that the SDoption is necessary to get good energy barriers while keeping the VB function compact in the BOVB framework. ${ }^{31}$ As a systematic tendency, the deviation of the SD-BOVB results relative to $\operatorname{CCSD}(\mathrm{T})$ increases regularly from $\mathrm{F}_{3}{ }^{-}$all the way to $\mathrm{I}_{3}{ }^{-}$but is never greater than $4 \mathrm{kcal} / \mathrm{mol}$. Another test for the SD-BOVB method is the calculation of the energy gap between the two exit channels of $\mathrm{X}_{3}{ }^{-}$, eqs 1 and 2, displayed in Table 3 . Once again, the accuracy is satisfactory relative to the $\operatorname{CCSD}(\mathrm{T})$ level, with a maximum deviation of $3.8 \mathrm{kcal} / \mathrm{mol}$ between the two computational methods, and in all cases the $\left(\mathrm{X}_{2}+\mathrm{X}^{-}\right)$dissociation channel appears to be the lowest one.

These good performances of a compact six-configuration VB wave function as compared to the best $\mathrm{MO}-\mathrm{CI}$ levels confirms that simple VB theory, provided it is used at its best level of accuracy, captures the essential bonding features of the hypervalent $\mathrm{X}_{3}{ }^{-}$complexes. In accord, the simplicity of the wave function will be exploited to get insight on the electronic states of the various complexes. The questions we are trying to answer are the following: (i) Are the $\mathrm{H}_{3}{ }^{-}$and trihalogen anion complexes of different bonding natures? (ii) Can the $\mathrm{X}_{3}{ }^{-}$barrier or dissociation energies be related to simple properties of the reactants, $\mathrm{X}_{2}+\mathrm{X}^{-}$? These questions can be answered by using VBCMDs of the type shown in Figure 1.

It is clear that the Lewis structures of the reactants and products (structures $\mathbf{1}-\mathbf{5}$, taken together) necessarily play an important role in the $\mathrm{X}_{3}{ }^{-}$complex. What is less obvious is the role of structure 6, which is included in the VB basis set for completeness, but which is a priori high-lying at any point of the diagram, owing to its nonbonding character. In order to appreciate the contribution of structure $\mathbf{6}$ to the stability of the various complexes, let us consider the VBCMDs restricted to structures $\mathbf{1 - 5}$, i.e., by ignoring the bold dotted line and the bold full lines, respectively, on top and on the bottom of the diagrams displayed in Figure $2 \mathrm{a}-\mathrm{e}$. The five-structure reaction profile, that is calculated by means of a variational SD-BOVB calculation involving structures $\mathbf{1 - 5}$ only, appears as the full thin line in each diagram. It can be seen that restricting the VB description to structures $\mathbf{1 - 5}$ does not fundamentally change the nature of the $\mathrm{X}_{3}{ }^{-}$complex for $\mathrm{H}_{3}{ }^{-}, \mathrm{Cl}_{3}{ }^{-}, \mathrm{Br}_{3}{ }^{-}$, and $\mathrm{I}_{3}{ }^{-}$, in that $\mathrm{H}_{3}{ }^{-}$remains a transition state, whereas the trihalogen anions are still stable intermediates. Thus, in each of these complexes, structure $\mathbf{6}$ only has a corrective effect. On the other hand, the five-structure reaction profile for $\mathrm{F}_{3}{ }^{-}$is qualitatively wrong, as it displays a reaction barrier instead of the expected potential well. The importance of structure $\mathbf{6}$ as a stabilizing factor may also be appreciated by comparing the five-structure barriers or dissociation energies, $\Delta E_{\mathrm{VB}-5}^{\ddagger}$, to the true barrier $\Delta E^{\ddagger}$ as calculated by a full six-structure SD-BOVB calculation (Table 4). The difference between the two sets of calculations ranges from 6 to $15 \mathrm{kcal} / \mathrm{mol}$ for $\mathrm{X}=\mathrm{H}, \mathrm{Cl}, \mathrm{Br}$, I, and jumps to 30 $\mathrm{kcal} / \mathrm{mol}$ for $\mathrm{X}=\mathrm{F}$.

Leaving aside the contribution of structure $\mathbf{6}$ for a while, it is interesting to relate the five-structure calculated barriers or dissociation energies to reactants' properties, by means of the VBCMDs. In these diagrams, the barrier $\Delta E_{\mathrm{VB}-5}^{\ddagger}$, be it positive or negative, can be expressed in terms of three parameters,

TABLE 4: Calculated Parameters of the Valence Bond Mixing Configuration Diagrams ${ }^{a}$

\begin{tabular}{lrrrrrrrr}
\hline & $\Delta E_{\mathrm{VB}-5^{b}}^{\ddagger}$ & $\Delta E^{\ddagger c}$ & $\Delta E_{\mathrm{c}}{ }^{b}$ & $B^{b}$ & $\Delta E_{\mathrm{ST}}{ }^{c, d}$ & $f^{b}$ & $D_{\mathrm{e}}{ }^{c, e}$ & $\Delta E_{\mathrm{ST}}-D_{\mathrm{e}}$ \\
\hline $\mathrm{H}_{3}{ }^{-}$ & 19.0 & 12.9 & 45.4 & 26.4 & 245.9 & 0.186 & 107.4 \\
$\mathrm{~F}_{3}{ }^{-}$ & 5.3 & -24.8 & 39.3 & 34.0 & 183.2 & 0.218 & 39.7 \\
$\mathrm{Cl}_{3}{ }^{-}$ & -9.5 & -23.4 & 25.4 & 34.9 & 175.0 & 0.173 & 50.0 \\
$\mathrm{Br}_{3}{ }^{-}$ & -16.8 & -28.6 & 15.9 & 32.7 & 140.0 & 0.142 & 42.8 \\
$\mathrm{I}_{3}{ }^{-}$ & -19.3 & -28.7 & 9.2 & 28.5 & 114.7 & 0.095 & 38.2 & 125.0 \\
& & & & & & &
\end{tabular}

${ }^{a}$ All energies are in kcal/mol. ${ }^{b}$ Calculated at the SD-BOVB level. ${ }^{c}$ Calculated at the CCSD(T) level. ${ }^{d}$ Singlet-triplet vertical transition energy of the $\mathrm{X}_{2}$ bond. ${ }^{e}$ Dissociation energy of the $\mathrm{X}_{2}$ bond. 


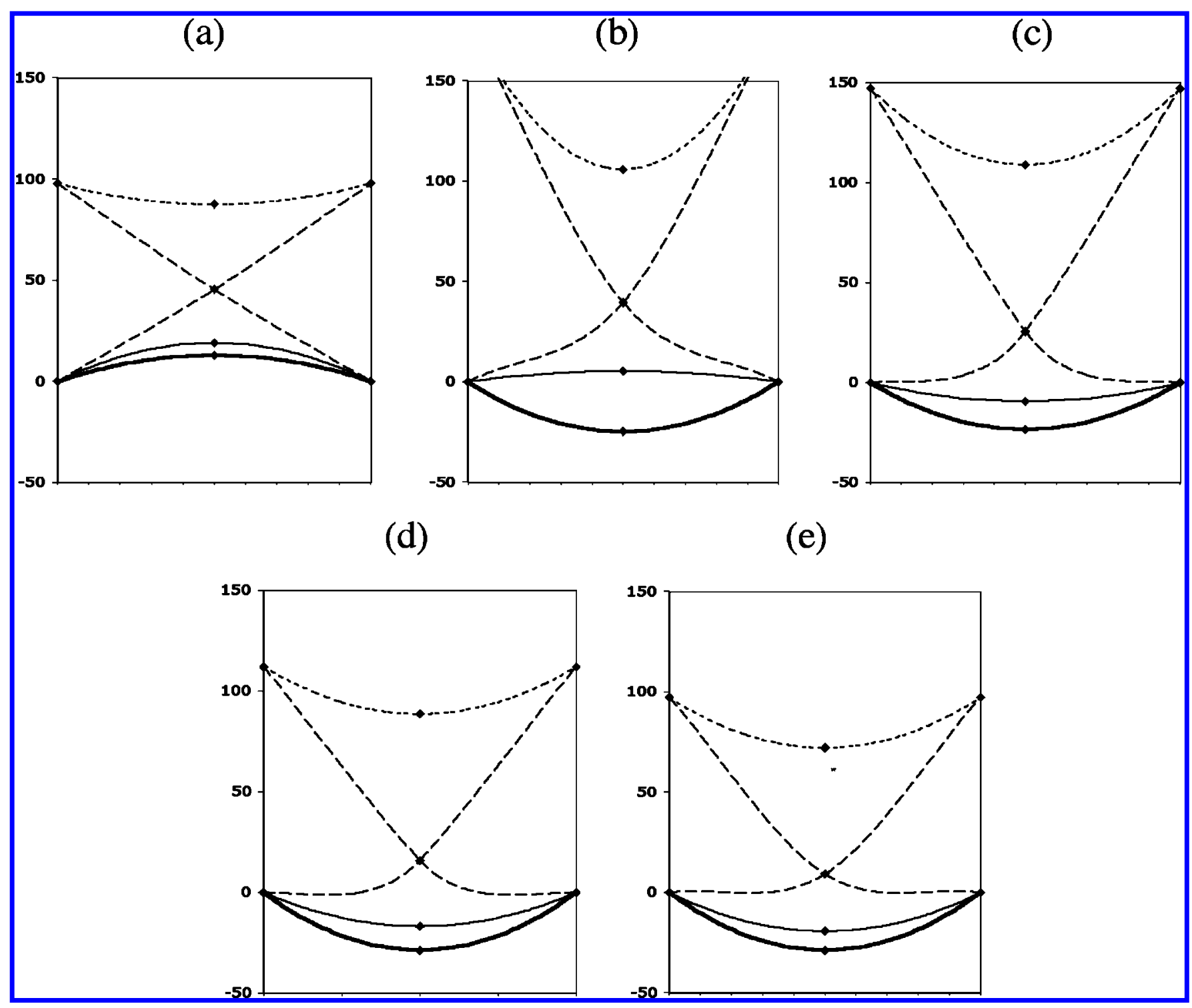

Figure 2. Quantitative valence bond mixing configuration diagram for the reaction $X_{2}+X^{-} \rightarrow\left[X_{3}\right]^{-} \rightarrow X^{-}+X_{2}$ : (a) $X=H$, (b) $X=F$, (c) $X$ $=\mathrm{Cl}$, (d) $\mathrm{X}=\mathrm{Br}$, (e) $\mathrm{X}=\mathrm{I}$. Energies are in $\mathrm{kcal} / \mathrm{mol}$.

TABLE 5: Weights of the Valence Bond Structures in the Ground State of $\mathrm{X}_{3}{ }^{-}$, as Calculated at the SD-BOVB Level

\begin{tabular}{lcccc}
\hline & $\mathbf{1}$ or $\mathbf{5}$ & $\mathbf{2}$ or $\mathbf{4}$ & $\mathbf{3}$ & $\mathbf{6}$ \\
\hline $\mathrm{H}_{3}{ }^{-}$ & 0.256 & 0.041 & 0.357 & 0.049 \\
$\mathrm{~F}_{3}{ }^{-}$ & 0.312 & 0.009 & 0.101 & 0.256 \\
$\mathrm{Cl}_{3}{ }^{-}$ & 0.327 & 0.019 & 0.163 & 0.154 \\
$\mathrm{Br}_{3}{ }^{-}$ & 0.320 & 0.022 & 0.163 & 0.152 \\
$\mathrm{I}_{3}{ }^{-}$ & 0.322 & 0.027 & 0.157 & 0.146
\end{tabular}

shown in Figure 1: $G$, the energy gap between the reactants and the VB structure of the products in the reactants' geometry; $\Delta E_{\mathrm{c}}$, the height of the crossing point of the diabatic curves relative to the reactants' energy; and $B$, the avoided-crossing resonance energy of the complex (Figure 1):

$$
\Delta E_{\mathrm{VB}-5}^{\ddagger}=\Delta E_{\mathrm{c}}-B
$$

To get an expression for $G$ that would be specific to the VBCMD at hand, ${ }^{38}$ let us consider the energy terms that enter in the promotion from $X_{2}+X^{-}$to $X^{\bullet}+X^{\bullet} X^{-}$, at fixed geometry. In this transition, the bonding energy of $\mathrm{X}_{2}$ is lost, while a Pauli repulsion builds up between $\mathrm{X}^{*}$ and $\mathrm{X}^{-}$. According to semiempirical $\mathrm{VB}$ theory, ${ }^{6}$ the absolute values of bonding energy and Pauli repulsion are nearly equal and sum up to $\Delta E_{\mathrm{ST}}$, the vertical singlet - triplet energy gap of the $\mathrm{X}_{2}$ bond. This latter parameter is therefore the key experimental quantity that corresponds to the promotion energy $G$, as expressed in eq 6 :

$$
G \approx \Delta E_{\mathrm{ST}}
$$

If now we express $\Delta E_{\mathrm{c}}$ as a fraction $f$ of the promotion energy $G$, and using eq 6 , the following final expression follows for the five-structure calculated barrier:

$$
\Delta E_{\mathrm{VB}-5}^{\ddagger}=f \Delta E_{\mathrm{ST}}-B
$$

As the quantity $f$ is directly related to the curvature of the diabatic curves, this parameter is usually called the "curvature factor". Note that the VB-calculated $G$ value might have been used instead of $\Delta E_{\mathrm{ST}}$ in eq 7 . The latter quantity is preferred for two reasons: (i) when large basis sets are used for anionic reactions, as is the case for $\mathrm{H}_{3}{ }^{-}$, the VB-calculated value of $G$ may be rather basis set dependent, whereas $\Delta E_{\mathrm{ST}}$ is not. The problem is encountered in $\mathrm{H}_{3}{ }^{-}$, where the low value of $G$ in Figure 2a is artifactual. (ii) $\Delta E_{\mathrm{ST}}$ is an easily accessible property, which does not require the use of a specific VB software. 
TABLE 6: Correlation between the Resonance Energy in the $\mathrm{X}_{2}^{-}$Three-Electron Bond and the Stabilizing Effect of Structure 6 in the $\mathrm{X}_{3}{ }^{-}$Ground State ${ }^{a}$

\begin{tabular}{lcc}
\hline $\mathrm{X}$ & $E\left(\mathrm{X}^{\cdot} \mathrm{X}^{-}\right)^{b}-E(\mathrm{X} \therefore \mathrm{X})^{b}$ & $\left(\Delta E_{\mathrm{V} \mathrm{B}-5}^{\ddagger}-\Delta E^{\ddagger}\right)^{c}$ \\
\hline $\mathrm{H}^{d}$ & & 6.1 \\
$\mathrm{~F}$ & 101.1 & 30.0 \\
$\mathrm{Cl}$ & 63.9 & 13.9 \\
$\mathrm{Br}$ & 52.6 & 11.8 \\
$\mathrm{I}$ & 51.5 & 9.4
\end{tabular}

${ }^{a}$ Energies are in $\mathrm{kcal} / \mathrm{mol}$. ${ }^{b}$ Calculated at the equilibrium geometry of $\mathrm{X}_{2}$, at the SD-BOVB level. ${ }^{c}$ Calculated at the equilibrium geometry of $\mathrm{X}_{3}^{-}$, at the SD-BOVB level. ${ }^{d}$ The three-electron-bonded $(\mathrm{H} \therefore \mathrm{H})^{-}$configuration is not stable.

Equation 7 is useful if the quantities on the right of the equal sign can be related to simple properties of the reactants. The $\Delta E_{\mathrm{ST}}$ parameter obviously fulfills this condition, since a singlet-triplet gap is experimentally observable or easily calculated by standard computational methods. The resonance energy $B$ is not a property of the reactants, but it can be seen that this quantity is fairly constant for the five reactions at hand, especially for the trihalogen anion dissociations which can be considered as reactions belonging to the same family. On the other hand, the curvature factor $f$ varies widely from $\mathrm{X}=\mathrm{H}$ all the way to $X=I$. Now it has been argued in the past ${ }^{3,39}$ that, for identity reactions for which the promotion energy $G$ can be approximated as $\Delta E_{\mathrm{ST}}$, the curvature factor can be correlated with the difference between two simple properties of the reactants (here $\mathrm{X}_{2}$ ): its singlet - triplet gap, $\Delta E_{\mathrm{ST}}$, and its bonding energy, $D_{\mathrm{e}}$. The larger this difference, the larger the curvature factor. It is indeed seen in Table 4 that $f$ correlates very nicely with $\left(\Delta E_{\mathrm{ST}}-D_{\mathrm{e}}\right)$, with a quasi-linear relationship. Thus, in the approximate model limited to $5 \mathrm{VB}$ structure, it appears that the barrier $\Delta E_{\mathrm{VB}-5}^{\ddagger}$ is entirely controlled by two easily accessible properties of the reactants. The interpretation of the barrier can be even more simplified if one notes that the $\left(\Delta E_{\mathrm{ST}}\right.$ $-D_{\mathrm{e}}$ ) difference is usually large for strong binders, and smaller for weak binders. In other words, $\left(\Delta E_{\mathrm{ST}}-D_{\mathrm{e}}\right)$ varies like $\Delta E_{\mathrm{ST}}$ alone. This allows us to correlate the $\Delta E_{\mathrm{VB}-5}^{\ddagger}$ values with a single parameter of $\mathrm{X}_{2}$, its singlet-triplet excitation energy $\Delta E_{\mathrm{ST}}$.

There now remains to include structure $\mathbf{6}$ in the calculations, in order to get the final wave functions and the corresponding barriers, which will be referred to in what follows as $\Delta E^{\ddagger}$. The weights of the various $\mathrm{VB}$ structures for $\mathrm{X}_{3}{ }^{-}$, as calculated at the SD-BOVB level, are displayed in Table 5. Expectedly, the ionic structures $\mathbf{2}$ and $\mathbf{5}$, bearing two adjacent negative charges, have a very small weight in all cases, owing to their instability. The triply ionic structure 3 is the major one in $\mathrm{H}_{3}{ }^{-}$, and smaller in $\mathrm{Cl}_{3}{ }^{-}, \mathrm{Br}_{3}{ }^{-}$, and $\mathrm{I}_{3}{ }^{-}$, but all in all these four species can be described mainly in terms of structures $\mathbf{1}, \mathbf{3}$, and $\mathbf{5}$, i.e., as an interplay of two Lewis structures, that of the reactants and that of the products. On the other hand, $\mathrm{F}_{3}{ }^{-}$is an exception and departs from the previous bonding picture, as having an exceptionally large contribution of structure 6 (25.6\%), by far the largest one among the five $\mathrm{X}_{3}{ }^{-}$species.

As structure 6 mixes with the Lewis structures in the $\mathrm{X}_{3}{ }^{-}$ geometry but not in the geometry of the reactants, it has the effect of lowering the barrier, relative to $\Delta E_{\mathrm{V}_{\mathrm{B}}-5}$. The differences between $\Delta E_{\mathrm{VB}-5}^{\ddagger}$ and $\Delta E^{\ddagger}$, as calculated at the SD-BOVB level, are shown in Table 6 . It is seen that these values display tendencies that are consistent with the weights of structure 6 in the various $\mathrm{X}_{3}{ }^{-}$species (Table 5): small for $\mathrm{H}_{3}{ }^{-}$, larger and slightly increasing in the series $\mathrm{I}_{3}{ }^{-}, \mathrm{Br}_{3}{ }^{-}$, and $\mathrm{Cl}_{3}{ }^{-}$, and much

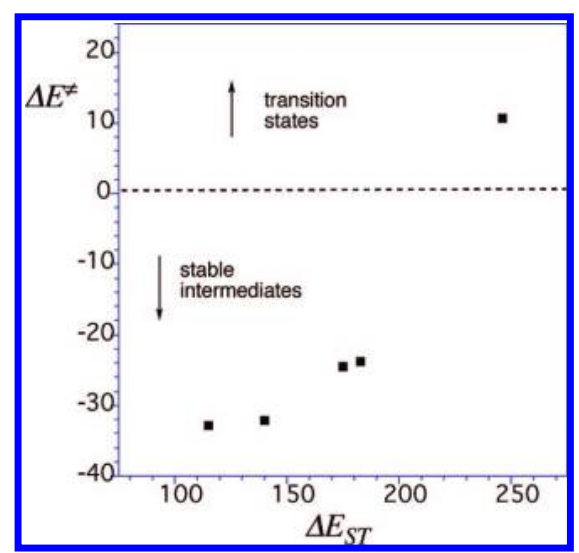

Figure 3. Correlation between $\Delta E^{\ddagger}$, the energy barrier for the reaction $\mathrm{X}_{2}+\mathrm{X}^{-} \rightarrow\left[\mathrm{X}_{3}\right]^{-} \rightarrow \mathrm{X}^{-}+\mathrm{X}_{2}$, and the vertical singlet-triplet gap of the $\mathrm{X}_{2}$ bond, $\Delta E_{\mathrm{ST}}$. All energies are calculated at the $\operatorname{CCSD}(\mathrm{T})$ level and expressed in $\mathrm{kcal} / \mathrm{mol}$.

larger for $\mathrm{F}_{3}{ }^{-}$which definitely proves to be bonded in a different way than the other hypervalent anions.

\section{Discussion}

It is now clear why $\mathrm{H}_{3}{ }^{-}$is a transition state, whereas $\mathrm{Cl}_{3}{ }^{-}$, $\mathrm{Br}_{3}{ }^{-}$, and $\mathrm{I}_{3}{ }^{-}$are stable intermediates (the case of $\mathrm{F}_{3}{ }^{-}$will be discussed later). The electronic structures of these four species can be approximately described as the interplay between the reactants' and products' Lewis structures, or 1-5. At this level, the barrier is approximated as $\Delta E_{\mathrm{VB}-5}^{\ddagger}$ and correlated with the vertical singlet-triplet gap of the $\mathrm{X}_{2}$ bond, $\Delta E_{\mathrm{ST}}$. This quantity is large for strong binders like hydrogen, and smaller for weak binders like halogens, resulting in a high-lying crossing point for $\mathrm{H}_{3}{ }^{-}$and a low-lying one for $\mathrm{Cl}_{3}{ }^{-}, \mathrm{Br}_{3}{ }^{-}$, and $\mathrm{I}_{3}{ }^{-}$. Given that the avoided-crossing energy $B$ is a roughly constant quantity, $\Delta E_{\mathrm{VB}-5}^{\ddagger}$ turns out to be positive for $\mathrm{X}=\mathrm{H}$ and negative (stable intermediate) for $\mathrm{X}=\mathrm{Cl}, \mathrm{Br}$, and $\mathrm{I}$. Improving the barrier estimation by including structure $\mathbf{6}$ in the calculation just makes a quantitative correction, which, however important, does not change the fundamental explanation. As a result, the good correlation that is found between $\Delta E_{\mathrm{ST}}$ and $\Delta E_{\mathrm{VB}-5}^{\ddagger}$ carries over to the true barrier, $\Delta E^{\ddagger}$.

The case of fluorine is special in several respects. Owing to a large lone-pair bond-weakening effect, ${ }^{40}$ the $\mathrm{F}_{2}$ molecule has a small $D_{\mathrm{e}}$ value that contrasts with a large singlet-triplet excitation energy $\Delta E_{\mathrm{ST}}$. The large $\left(\Delta E_{\mathrm{ST}}-D_{\mathrm{e}}\right)$ difference results in a large $f$ factor (Table 4 ) and contributes to raise the fivestructure barrier, $\Delta E_{\mathrm{VB}-5}^{\ddagger}$. This effect is, however, compensated by a very large stabilizing effect of structure 6 (see Figure $2 b$ ), leading to a final dissociation energy for $\mathrm{F}_{3}{ }^{-}$that is close to that of $\mathrm{Cl}_{3}{ }^{-}$. All in all, the $\Delta E^{\ddagger}$ values for all $\mathrm{X}_{3}{ }^{-}$species, including $\mathrm{F}_{3}{ }^{-}$, nicely correlate with the corresponding $\Delta E_{\mathrm{ST}}$ values of the $\mathrm{X}_{2}$ molecules, as shown in Figure 3. Even if the correlation is far from being linear, still $\Delta E_{\mathrm{ST}}$ clearly appears as the unique quantity that rules the stability of $\mathrm{X}_{3}{ }^{-}$relative to $\mathrm{X}_{2}+\mathrm{X}^{\bullet}$.

The key role of structure $\mathbf{6}$ in $\mathrm{F}_{3}{ }^{-}$deserves some further comments. This structure, which contributes one-quarter of the total wave function, endows the complex with an important three-electron bonding character. Indeed, as illustrated in eqs 8 and 9, the association of $\mathbf{1}$ and $\mathbf{6}$ is nothing else but the VB expression for a three-electron bond between $\mathrm{X}_{\mathrm{b}}$ and $\mathrm{X}_{\mathrm{c}}$, whereas $5+6$ represent another three-electron bond, now between $X_{a}$ and $\mathrm{X}_{\mathrm{b}}$ : 


$$
\begin{aligned}
& \mathbf{1} \leftrightarrow \mathbf{6} \equiv \mathrm{X}^{*}[\mathrm{X} \therefore \mathrm{X}]^{-} \\
& \mathbf{5} \leftrightarrow \mathbf{6} \equiv[\mathrm{X} \therefore \mathrm{X}]^{-} \mathrm{X}^{\cdot}
\end{aligned}
$$

This three-electron bonding character explains why the dissociation of $\mathrm{F}_{3}{ }^{-}$at high collision energy produces 3 times more $\mathrm{F}_{2}{ }^{-}$than $\mathrm{F}_{2}$ : dissociation just follows diabatically the exit channel 2, which is the most reminiscent of the bonding nature of the complex, even if thermochemistry would favor channel $1 .^{30}$ On the other hand, as can be seen from the weights of structure 6 displayed in Table 5, the three-electron bonding character is not very important in $\mathrm{Cl}_{3}{ }^{-}, \mathrm{Br}_{3}{ }^{-}$, and $\mathrm{I}_{3}{ }^{-}$, which can be described in terms of standard Lewis structures displaying two-electron bonds. In accord, these three species dissociate via the thermodynamically favored exit channel, reaction 1 .

One question that is still unresolved at this point is why structure $\mathbf{6}$ contributes so much to the stability of $\mathrm{F}_{3}{ }^{-}$and much less to the other species, or in other word why the $\left(\Delta E_{\mathrm{V} B}^{\ddagger}-5-\right.$ $\Delta E^{\ddagger}$ ) difference is $2-3$ times larger in $\mathrm{F}_{3}{ }^{-}$than in the other trihalogen anions (Table 6). This large resonance energy, mainly due to the mixing of structure $\mathbf{6}$ with the covalent structures $\mathbf{1}$ and $\mathbf{5}$, is reminiscent of the exceptionally large resonance energy that arises from the mixing of covalent and ionic structures in the two-electron bond of $\mathrm{F}_{2} \cdot{ }^{41}$ As the latter VB structures, $\mathrm{F} \cdot-\cdot \mathrm{F}$ and $\left(\mathrm{F}^{+} \mathrm{F}^{-}+\mathrm{F}^{-} \mathrm{F}^{+}\right)$, differ from each other by a single electron transfer, the corresponding resonance energy has been called "charge-shift resonance energy". So large is this quantity in the $F_{2}$ molecule $(67 \mathrm{kcal} / \mathrm{mol})$ that it is the only term that sustains bonding, whereas by contrast the covalent term, by itself, is repulsive at any interatomic distance. ${ }^{30,41}$ On the other hand, the other halogens, chlorine, bromine, and presumably iodine, are less and less prone to charge-shift bonding than fluorine. ${ }^{42}$

Given that charge-shift resonance energy characterizes the mixing of structures differing by a single electron transfer in the two-electron case, there is no reason why the concept could not be extended to $\mathrm{X}_{3}{ }^{-}$since $\mathbf{1}$ or $\mathbf{5}$ both differ from $\mathbf{6}$ by a single electron transfer. Thus, assuming that the same mixing rules apply to the $\mathrm{X}_{3}{ }^{-}$and $\mathrm{X}_{2}$ VB structures, one would predict that the mixing of $\mathbf{1}$ (or $\mathbf{5}$ ) and $\mathbf{6}$, leading to three-electron bonding, is much more stabilizing in $\mathrm{F}_{3}{ }^{-}$than in the other trihalogen anions. This reasoning can be given quantitative support by calculating the charge-shift resonance energy arising from the mixture of the $\mathrm{X}^{-} \mathrm{X}^{\cdot}$ and $\mathrm{X}^{\cdot} \mathrm{X}^{-}$structures in the threeelectron-bonded $\mathrm{X}_{2}^{-}$species. The corresponding stabilization energy, $\Delta E(3-\mathrm{e})$, defined in eq 10, is displayed in Table 6 along with the $\left(\Delta E_{\mathrm{V} B-5}^{\ddagger}-\Delta E^{\ddagger}\right)$ values.

$$
\Delta E(3-\mathrm{e})=E\left(\mathrm{X}^{-} \mathrm{X}^{\bullet}\right)-E\left([\mathrm{X} \therefore \mathrm{X}]^{-}\right)
$$

It is seen from the $\Delta E(3-\mathrm{e})$ values that the three-electron interaction is particularly stabilizing in $\mathrm{F}_{2}{ }^{-}$, while being much smaller in the other dihalogen anions, and slightly decreasing in the order $\mathrm{Cl}_{2}{ }^{-}, \mathrm{Br}_{2}{ }^{-}$, and $\mathrm{I}_{2}{ }^{-}$. Exactly the same tendencies are seen in the stabilizing effect of structure $\mathbf{6}$, quantified as $\left(\Delta E_{\mathrm{V}_{\mathrm{B}}-5}-\Delta E^{\ddagger}\right)$ difference, which correlates very well with $\Delta E(3-\mathrm{e})$ in Table 6. This large stabilization in the $\mathrm{F}_{3}{ }^{-}$case is the reason why this complex has a major three-electron bonding character ${ }^{30}$ and dissociates to $\mathrm{F}_{2}{ }^{-}+\mathrm{F}^{*}$ at large collision energies.

\section{Conclusion}

The $\mathrm{X}_{3}{ }^{-}$hypercoordinated anions $(\mathrm{X}=\mathrm{H}, \mathrm{F}, \mathrm{Cl}, \mathrm{Br}, \mathrm{I})$ have been studied by means of the BOVB ab initio method. The wave functions for the $\mathrm{X}_{3}{ }^{-}$species are extremely simple as they involve only six configurations, all of which have a clear physical meaning in terms of valence bond structures. Despite this compactness, the BOVB method provides accurate positive or negative barriers for the $\mathrm{X}_{2}+\mathrm{X}^{-} \rightarrow \mathrm{X}^{-}+\mathrm{X}_{2}$ exchange reaction, as well as accurate transition energies for the two different exit channels for the $\mathrm{X}_{3}{ }^{-}$dissociation, as compared to the reference $\operatorname{CCSD}(\mathrm{T})$ computational level. These results are interpreted in the framework of valence bond mixing correlation diagrams, which show that the barrier/dissociation energies are governed by a single property of the reactants, the vertical singlet-triplet transition energy $\Delta E_{\mathrm{ST}}$ of the $\mathrm{X}_{2}$ molecule. Thus, as $\mathrm{H}_{2}$ has a large $\Delta E_{\mathrm{ST}}$ value, the exchange reaction barrier is positive for $\mathrm{X}=\mathrm{H}$, indicating that $\mathrm{H}_{3}{ }^{-}$is an unstable transition state. On the other hand, a smaller $\Delta E_{\mathrm{ST}}$ value for $\mathrm{F}_{2}$ and $\mathrm{Cl}_{2}$ leads to a negative barrier for the exchange reactions, indicating that $\mathrm{F}_{3}{ }^{-}$and $\mathrm{Cl}_{3}{ }^{-}$are stable intermediates. Lastly, even smaller $\Delta E_{\mathrm{ST}}$ values for $\mathrm{Br}_{2}$ and $\mathrm{I}_{2}$ nicely agree with the fact that $\mathrm{Br}_{3}{ }^{-}$ and $\mathrm{I}_{3}{ }^{-}$are the most stable hypercoordinated anions of the series. Thus, the main conclusion that emerges from this study is that valence bond correlation diagrams provide a much better model than the traditional Rundle-Pimentel model for hypervalency in four-electron-three-center systems. It is interesting to note that the singlet-triplet gap of the dimer is the basic ingredient $J$ of the magnetic treatment of half-filled band systems. In this respect, the halogen trimer anion, as a four-electron-three-center system, is a doped half-filled band. For such systems the basic model Hamiltonian is the so-called $t-J$ model, first introduced in chemistry by Gadea et al., ${ }^{43}$ now famous in the study of highTc superconductors.

Examination of the valence bond wave functions shows that $\mathrm{H}_{3}{ }^{-}, \mathrm{Cl}_{3}{ }^{-}, \mathrm{Br}_{3}{ }^{-}$, and $\mathrm{I}_{3}{ }^{-}$have about the same bonding picture and can be described as an interplay between two Lewis structures, that of the reactants and products in the exchange reaction. For these anions, the nonbonding structure $\mathbf{6}$ is necessary to get quantitative energetics but has only a corrective effect that is very weak in $\mathrm{H}_{3}{ }^{-}$, more important in the trihalogens. By contrast, structure $\mathbf{6}$ plays a fundamental role in $\mathrm{F}_{3}{ }^{-}$, as it accounts for one-quarter of the wave function in terms of weights and has a prominent stabilizing effect. This structure endows the ground state of $\mathrm{F}_{3}{ }^{-}$with an important threeelectron bonding character, which is the reason why this complex dissociates by the thermodynamically less favored exit channel, $\mathrm{F}_{2}^{-}+\mathrm{F}^{*}$, whereas the other trihalogen anions dissociate to most stable products $\mathrm{X}_{2}+\mathrm{X}^{-}$, as expected from thermodynamic control. This large contribution of structure 6 in $\mathrm{F}_{3}{ }^{-}$is to be related to a property that has already been shown to be a characteristic of the two-electron and three-electron bonds in $\mathrm{F}_{2}$ or $\mathrm{F}_{2}{ }^{-}$, namely, the exceptionally large charge-shift resonance energy that is associated to the mixing of VB structures differing from each other by a single electron shift. ${ }^{41}$ Large charge-shift resonance energies define a specific category of bonds which have already been shown to display peculiar experimental manifestations like depletion of electronic density in the middle of the bond, ${ }^{41}$ large barrier in the $\mathrm{H}^{\bullet}+\mathrm{FH} \rightarrow \mathrm{HF}+\mathrm{H}^{\bullet}$ exchange reaction, ${ }^{42}$ reluctance of the $\mathrm{Si}-\mathrm{X}$ bond to heterolyze in solution, ${ }^{44}$ and so on. In this context, the counterintuitive dissociation of $\mathrm{F}_{3}{ }^{-}$to the highest exit channel is nothing else but another experimental manifestation of large charge-shift resonance energy in fluorine compounds.

Acknowledgment. We are grateful to Professor W. Wu for making the latest version of the XMVB valence bond program available to us.

\section{References and Notes}

(1) Shaik, S. S. J. Am. Chem. Soc. 1981, 103, 3692.

(2) Shaik, S.; Shurki, A. Angew. Chem. Int. Ed. 1999, 38, 586. 
(3) Shaik, S.; Hiberty, P. C. Adv. Ouantum Chem. 1995, 26, 99.

(4) Pross, A. Theoretical and Physical Principles of Organic Reactivity; John Wiley and Sons, Inc.: New York, 1995; pp83-124 and 235-290.

(5) Shaik, S.; Hiberty, P. C. Rev. Comput. Chem. 2004, $20,1$.

(6) Shaik, S.; Hiberty, P. C. A Chemist's Guide to Valence Bond Theory; Wiley Interscience: New York, 2007.

(7) Maître, P.; Hiberty, P. C.; Ohanessian, G.; Shaik, S. S. J. Phys. Chem. 1990, 94, 4089.

(8) (a) Sini, G.; Hiberty, P. C.; Shaik, S. S. J. Chem. Soc., Chem. Commun. 1989, 772. (b) Sini, G.; Ohanessian, G.; Hiberty, P. C.; Shaik, S. S. J. Am. Chem. Soc. 1990, 112, 1407.

(9) For a different model of hypervalency of silicon vs carbon, see: (a) Pierrefixe, S. C. A. H. Struct. Chem. 2007, 18, 813. (b) Pierrefixe, S. C. A. H.; Guerra, C. F.; Bickelhaupt, F. M. Chem. Eur. J. 2008, 14, 819

(10) Sini, G.; Maître, P.; Hiberty, P. C.; Shaik, S. S. Inorg. Chem. 1990 29, 3047.

(11) Ault, B. S.; Andrews, L. J. Am. Chem. Soc. 1976, 98, 1591.

(12) Ault, B. S.; Andrews, L. Inorg. Chem. 1977, 16, 2024

(13) (a) Ault, B. S.; Andrews, L. J. Chem. Phvs. 1976, 64, 4853. (b)

Ault, B. S.; Andrews, L. J. Am. Chem. Soc. 1975, 97, 3824. (c) Evans,

J. C.; Lo, G. Y.-S. J. Chem. Phvs. 1966, 44, 3638

(14) (a) Person, W. B.; Anderson, G. R.; Fordemwalt, J. N.; Stammreich,

H.; Forneris, R. J. Chem. Phvs. 1961, 35, 908. (b) Kiefer, W.; Bernstein,

H. J. Chem. Phys. Lett. 1972, 15, 5. (c) Parret, F. W.; Tailor, N. J. J. Inorg Nucl. Chem. 1970, 32, 2458. (d) Gabes, W.; Gerding, H. J. Mol. Struct. 1972, 14, 267

(15) (a) Mohmmad, M. R.; Sherman, W. F. J. Mol. Struct. 1984, 115,

27. (b) Loos, K. R.; Jones, A. C. J. Chem. Phvs. 1974, 78, 2306.

(16) Bogaard, M. P.; Peterson, J.; Rae, A. D. Acta Crvstallogr., Sect. B 1981, 37, 1357.

(17) (a) Cotton, F. A.; Lewis, G. E.; Schwetzer, W. Inorg. Chem. 1986 25, 3528, and references therein. (b) Rosshirt, E. F.; Frey, F.; Boysen, H.; Jagodzinski, H. Acta Crvstallogr., Sect. B 1985, 41, 66.

(18) Hogness, T. R.; Harkness, R. W. Phys. Res. 1928, 32, 784

(19) Melton, C. E.; Ropp, G. A.; Rudolph, P. S. J. Chem. Phvs. 1958, 29,968

(20) Sides, G. D.; Tiernan, T. O.; Hanrahan, R. J. J. Chem. Phys. 1976, $65,1966$.

(21) Tuinman, A. A.; Gakh, A. A.; Hinde, R. J.; Compton, R. N. J. Am. Chem. Soc. 1999, 121, 8397.

(22) Do, K.; Klein, T. P.; Pommerening, C. A.; Sunderlin, L. S. J. Am. Soc. Mass Spectrom. 1997, 8, 688.

23) Nizzi, K. E.; Pommerening, C. A.; Sunderlin, L. S. J. Phys. Chem. A 1998, 102,7674.

(24) Artau, A.; Nizzi, K. E.; Hill, B. T.; Sunderlin, L. S.; Wenthold,

P. G. J. Am. Chem. Soc. 2000, 122, 10667.

(25) Keil, F.; Ahlrichs, R. J. Am. Chem. Soc. 1976, 98, 4787.

(26) Pauling, L. The Nature of the Chemical Bond, 3rd ed.; Cornell University Press: Ithaca, NY, 1960; p 145.

(27) Reed, A. E.; Schleyer, P. v. R. J. Am. Chem. Soc. 1990, 112, 1434, and references therein.

(28) (a) Hach, R. J.; Rundle, R. E. J. Am. Chem. Soc. 1951, 73, 4321.

(b) Pimentel, C. G. J. Chem. Phys. 1951, 19, 446.

(29) Munzarova, M. L.; Hoffmann, R. J. Am. Chem. Soc. 2002, 124 4787.

(30) Braïda, B.; Hiberty, P. C. J. Am. Chem. Soc. 2004, 126, 14890.
(31) (a) Hiberty, P. C.; Flament, J. P.; Noizet, E. Chem. Phvs. Lett. 1992, 189, 259. (b) Hiberty, P. C.; Humbel, S.; Byrman, C. P.; van Lenthe, J. H. J. Chem. Phys. 1994, 101, 5969. (c) Hiberty, P. C.; Shaik, S. Theor. Chem. Acc. 2002, 108, 255. (d) Hiberty, P. C.; Shaik, S. J. Comput. Chem. 2007, 28,185 .

(32) (a) Rumer, G. Nachr. Ges. Wiss. Goettingen, Math.-Phys. Kl. 1932, 337. (b) Pauncz, R. Spin Eigenfunctions; Plenum Press: New York, 1979.

(33) (a) Dunning, T. H. J. Chem. Phys. 1989, 90, 1007. (b) Kendall, R. A.; Dunning, T. H., Jr.; Harrison, R. J. J. Chem. Phys. 1992, 96, 6796. (c) Woon, D. E.; Dunning, T. H. J. Chem. Phys. 1993, 98, 1358.

(34) Peterson, K. A.; Figgen, D.; Goll, E.; Stoll, H.; Dolg, M. J. Chem. Phys. 2003, 119, 11113

(35) Frisch, M. J.; Trucks, G. W.; Schlegel, H. B.; Scuseria, G. E.; Robb, M. A.; Cheeseman, J. R.; Zakrzewski, V. G.; Montgomery, J. A., Jr.; Stratmann, R. E.; Burant, J. C.; Dapprich, S.; Millam, J. M.; Daniels, A. D.; Kudin, K. N.; Strain, M. C.; Farkas, O.; Tomasi, J.; Barone, V.; Cossi, M.; Cammi, R.; Mennucci, B.; Pomelli, C.; Adamo, C.; Clifford, S.; Ochterski, J.; Petersson, G. A.; Ayala, P. Y.; Cui, Q.; Morokuma, K.; Malick, D. K.; Rabuck, A. D.; Raghavachari, K.; Foresman, J. B.; Cioslowski, J.; Ortiz, J. V.; Stefanov, B. B.; Liu, G.; Liashenko, A.; Piskorz, P.; Komaromi, I.; Gomperts, R.; Martin, R. L.; Fox, D. J.; Keith, T.; Al-Laham, M. A.; Peng, C. Y.; Nanayakkara, A.; Gonzalez, C.; Challacombe, M.; Gill, P. M. W.; Johnson, B. G.; Chen, W.; Wong, M. W.; Andres, J. L.; Head-Gordon, M.; Replogle, E. S.; Pople, J. A. Gaussian 98; Gaussian, Inc.: Pittsburgh, PA, 1998.

(36) (a) Song, L.; Wu, W.; Mo, Y.; Zhang, Q. XMVB: An Ab Initio Nonorthogonal Valence Bond Program; Xiamen University: Xiamen, China, 1999. (b) Song, L.; Mo, Y.; Zhang, Q.; Wu, W. J. Comput. Chem. 2005, 26, 514.

(37) (a) Clark, T. J. Am. Chem. Soc. 1988, 110, 1672. (b) Gill, P. M. W. Radom, L. J. Am. Chem. Soc. 1988, 110, 4931. (c) Braïda, B.; Hiberty, P. C. J. Phys. Chem. A 2000, 104, 4628. (d) Braïda, B.; Lauvergnat, D.; Hiberty, P. C. J. Chem. Phys. 2001, 115, 90.

(38) The expression for the gap $G$ depends on which type of VB correlation diagram is considered. In a simple VBSCD, which describes the reaction as an interplay on only two diabatic structures, the promotion energy $G$ for reaction 4 would correspond to the transition from $\left(\mathrm{X}^{-}+\right.$ $\mathrm{X}-\mathrm{X})$ to $\left(\mathrm{X}^{\cdot}+[\mathrm{X} \therefore \mathrm{X}]^{-}\right)$. In such a case, $G$ is estimated as the ionization potential of $\mathrm{X}^{-}$minus the electron affinity of $\mathrm{X}_{2}$. For the application of a VBSCD to $\mathrm{H}_{3}{ }^{-}$and $\mathrm{F}_{3}{ }^{-}$, see ref 28 .

(39) Shaik, S.; Wu, W.; Dong, K.; Song, L.; Hiberty, P. C. J. Phys. Chem. A 2000, 105, 8226 .

(40) (a) Shaik, S.; Maître, P.; Sini, G.; Hiberty, P. C. J. Am. Chem. Soc. 1992, 114, 7861. (b) Lauvergnat, D.; Hiberty, P. C. J. Mol. Struct. (THEOCHEM) 1995, 338, 283. (c) Hiberty, P. C.; Ramozzi, R.; Wu, W.; Shaik, S. Faradav Discuss. 2007, 135, 261.

(41) Shaik, S.; Danovich, D.; Silvi, B.; Lauvergnat, D.; Hiberty, P. C. Chem. Eur. J. 2005, 11, 6358.

(42) Hiberty, P. C.; Megret, C.; Song, L.; Wu, W.; Shaik, S. J. Am. Chem. Soc. 2006, 128, 2836.

(43) Gadea, F. X.; Maynau, D.; Malrieu, J. P. Int. J. Quantum Chem. 1984, $26,1$.

(44) Su, P.; Song, W.; Wu, W.; Shaik, S.; Hiberty, P. C. J. Phys. Chem. A 2008, 112, 2988.

JP803808E 